Original Research Paper

\title{
Utilization of Rumen Content by Indigenous Microorganisms in a Modified Anaerobic Digester
}

\author{
${ }^{1}$ Alhassan Salihu Adam, ${ }^{2}$ Sani Yahaya, \\ ${ }^{3}$ Haruna Musa, ${ }^{4}$ Kasim Mohammed and ${ }^{2}$ Muhammad Dauda Mukhtar \\ ${ }^{I}$ Centre for Renewable Energy Research, Bayero University, Kano (BUK), Nigeria \\ ${ }^{2}$ Department of Microbiology, BUK, Nigeria \\ ${ }^{3}$ Department of Pure and Industrial Chemistry, BUK, Nigeria \\ ${ }^{4}$ Department of Civil Engineering, BUK, Nigeria
}

\author{
Article history \\ Received: 08-08-2020 \\ Revised: 21-09-2020 \\ Accepted: 26-09-2020 \\ Corresponding Author: \\ Alhassan Salihu Adam \\ Centre for Renewable Energy \\ Research, Bayero University, \\ Kano (BUK), Nigeria \\ Email:askdbest@gmail.com
}

Abstract: The current work was designed to assess the effect of modification of model digester on the kinetics that affects efficiency in biogas generation using bovine rumen content as the feedstock. A biogas plant consisting of conventional and modified fixed-dome digesters (each with $2 \mathrm{~m}^{3}$ capacity) was established; and bovine rumen content was used as feedstock. Standard methods were used to determine the kinetic (physicochemical and microbiological) parameters. Identification of fungal and bacterial species involved in the process was carried out by genomic study of the $18 \mathrm{~S}$ rRNA and 16S rRNA regions, respectively; amplified using universal forward and backward primers for fungi (NS1/NS4), bacteria ((515F/926R) and archaea (Met86F/Met140R); submitted to GenBank and analysed using Blast Programme at National Centre for Biotechnology Information website. A mass balance approach was used to estimate the theoretical gas yield from the total solid/volatile sold lost. It was found that the temperature in both modified and conventional digesters was uniform throughout the hydraulic retention time, between 32 to $34.5^{\circ} \mathrm{C}$, indicating a mesophilic range. The $\mathrm{pH}$ level was found to be lower in the modified digester compared to the conventional digester, indicating higher accumulation of organic acids. The mean total solid was found to drop from $12.49 \pm 0.53$ to $3.82 \pm 0.21$ in the modified digester after digestion, while this was from $13.30 \pm 0.4$ to $6.69 \pm 0.16$ in the conventional digester. The mean volatile solid drops from $66.67 \pm 1.62$ to $36.13 \pm 0.27$ in the modified digester after digestion, while it was from $69.94 \pm 1.54$ to $54.23 \pm 1.33$ in the conventional digester. The theoretical biogas yield was higher in the modified digester $(87 \mathrm{mg} / \mathrm{l})$ compared to the conventional one $(65 \mathrm{mg} / \mathrm{l})$. The microbial counts were observed to be affected by the kinetic parameters in both the digesters. The organisms identified were: Lactobacillus acidophilus, Bacteroides nordii, Clostridium perfringens, Clostridium acetobutylicum, Proteus vulgaris, Methanosarcina sicilia, Methanosarcina mazei, Methanobrevibacter ruminantium, Fusarium solani, Fusarium graminearum, Aspergillus niger and Penicillium specie. Conclusively, the modified digester, under a manual stirring at 10 round/min, 3 times a day at an interval of six hours, has appreciably generated higher theoretical biogas yield after 8 weeks hydraulic retention time. The agitation of the slurry using the improvised stirrer in the modified digester has significantly facilitated the utilization of the bovine rumen content by the indigenous microorganisms. Modification of digester to enhance mixing of the feedstock should therefore be encouraged in household anaerobic digesters.

Keywords: Anaerobic Digestion, Rumen Content, Indigenous Microorganisms, Modified Digester 


\section{Introduction}

Over the past few decades, there has been a substantial increase in research and development in the area of biofuels. Many researchers around the world have dealt with environmental, economic, policy and technical subjects aspects relating to these studies (Aurélio, 2011). Biofuels are the potential and sustainable alternative sources of energy. Despite having tremendous efforts toward development of economically competitive biofuels, substantial move is yet to be made and the outcomes are still far from practical implementation globally (Chandel, 2019). One of the key issues in this respect is the conversion of the biodegradable feedstock to the desired biofuel. Anaerobic Digestion (AD) is one of the promising technologies for recovering energy from the organic fraction of municipal solid waste and other biodegradable waste. It is a series of biological processes that use a diversed population of microorganisms to break down organic materials into biogas, primarily methane and a combination of solid and liquid effluents, the digestate. It occurs in the absence of free oxygen (Sebola et al., 2013). Such a conversion is driven by several factors including type and nature of feedstock, technology applied physicochemical parameters, microorganisms involved, etc. (Miertus, 2007).

Of the various factors that determine biogas yield, feedstock selection remains one of the most crucial steps in anaerobic digestion processes; digestibility and nutritional composition are considered in this respect. The use of bovine rumen content from slaughterhouse has been reported to contain a good level of both macro and micronutrients (trace elements). However, digestibility and nutritional composition might be different among bovines influenced by the (1) feeding regimen, (2) length of the holding time between feeding and slaughter, (3) season, (4) feed resource diversity and (5) selection of pastures by various animals in various areas (Cherdthong et al., 2014).

The performance of anaerobic digesters is also affected by the retention time of substrate in the digester and the degree of contact between incoming substrate and a viable microbial population. These parameters are primarily a function of the hydraulic regime (mixing) in the reactors. The importance of mixing in achieving efficient substrate conversion has been noted by many researchers, although the optimum mixing pattern is a subject of much debate. Mixing of the substrate in the digester helps to distribute organisms uniformly throughout the substrate (Karim et al., 2003).

Furthermore, agitation aids in particle size reduction as digestion progresses and in removal of gas from the mixture (Karim et al., 2005). The two very important aspects of digester mixing are the intensity and duration of mixing. Most of the literature on anaerobic digestion emphasizes the importance of adequate mixing to improve the distribution of substrates, enzymes and microorganisms throughout the digester (Parkin and Owen, 1986; Chapman, 1989; Lema et al., 1991). However, the information available in the literature about the effect of the intensity and duration of mixing on the performance of anaerobic digesters are contradictory. Several studies indicated that a lack of sufficient mixing in low solids digesters dealing with municipal waste resulted in a floating layer of solids (Diaz and Trezek, 1977; James et al., 1980; Stenstrom et al., 1983). Chen et al. (1990) observed higher methane yield in the case of a $4.5 \mathrm{~m}^{3}$ digester under unmixed conditions than continuously mixed conditions. In another study, (Ben-Hasson et al., 1985) observed $75 \%$ lower methane production rate from dairy cattle manure under continuously mixed conditions than unmixed conditions. On the contrary, (Ho and Tan, 1985) reported greater gas production for a continuously mixed digester than for an unmixed digester fed with palm oil mill effluents and (Hashimoto, 1983) found higher biogas production from beef cattle wastes under continuously mixed conditions than under intermittent mixing conditions. At the same time, (Dague et al., 1970; Mills, 1979; Smith et al., 1979) recommended intermittent mixing of anaerobic digesters over continuous mixing. It was with this view that the present study was designed to find out if modifying the household conventional anaerobic digester would improve biogas yield.

\section{Materials and Methods}

\section{Establishment of Biogas Plant}

The construction manual for modified (Georgia Gwinnett College [GGC] Model for Pakistan, 2009) was used in the present study to guide the construction of $2 \mathrm{~m}^{3}$ fixed-dome anaerobic digesters (Fig. 1). After construction, one digester was modified by improvising it with a mechanical stirrer, while the other was not; this was meant to compare the kinetics of biogas production. The construction was based on the locally available materials.

\section{Feedstock Selection, Collection and Feeding of Digesters}

Bovine rumen content was selected in this research to be used as feedstock; this was in consideration of its abundance at the abattoirs around Kano. A large quantity of fresh bovine rumen content was collected in large polypropylene bags (Nigerian Bag Manufacturing BAGCO) from Kano main abattoir, along IBB Road, Dala Local Government Area, Kano State. The holding capacity of each digester was about 2000 litres and based on this, each digester was fed with fresh rumen content to occupy two-third of the total capacity; and clean water was introduced to fill up the remaining space to make a slurry with total solid of 11.8 and $12.3 \%$ in the modified and conventional digesters, respectively. A manual stirring at $10 \mathrm{round} / \mathrm{min}, 3$ times a day at an interval of six hours was ensured. 


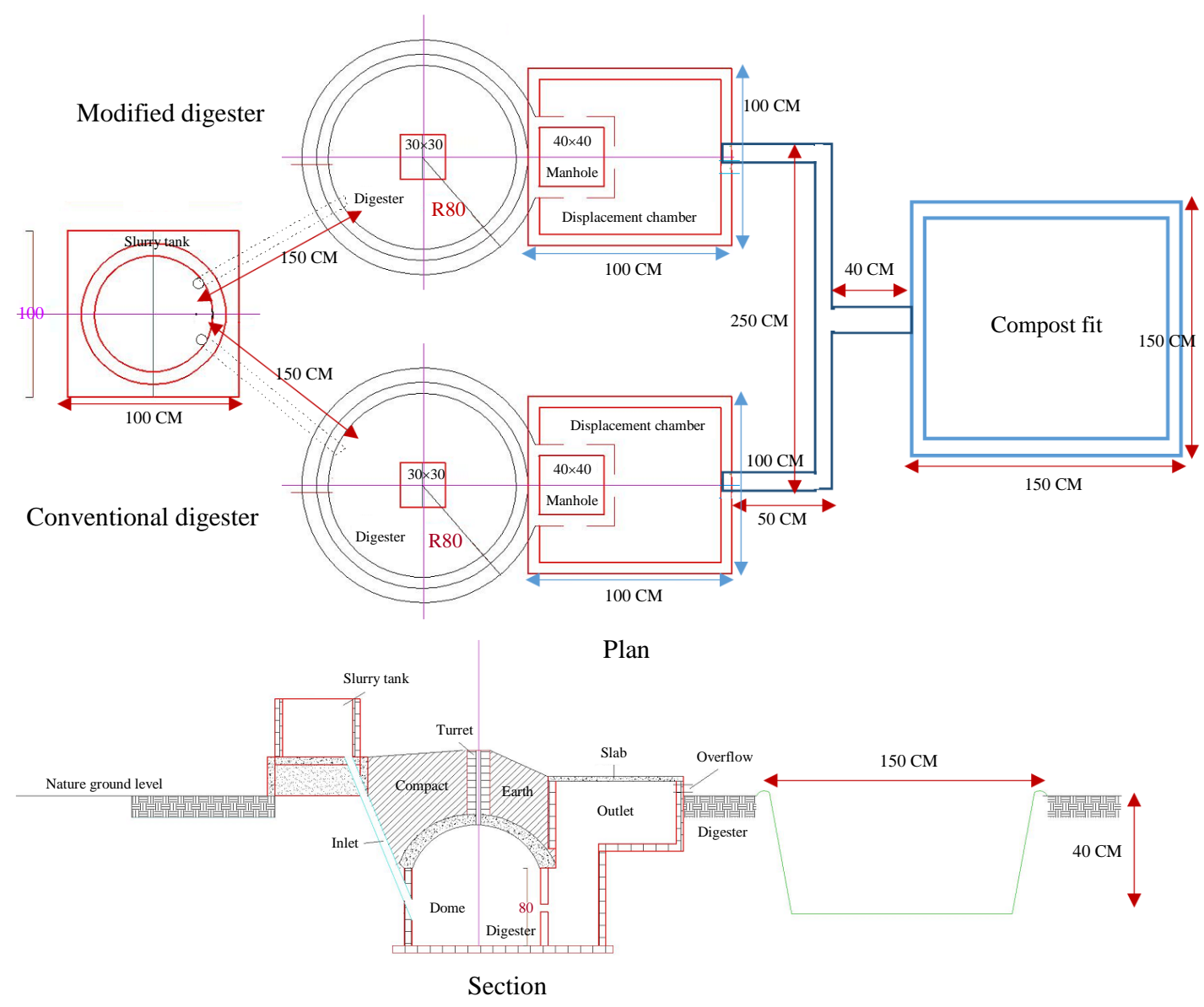

Fig. 1: Architectural plan of the biogas plant

\section{Analytical Procedures}

\section{Physicochemical Analyses}

Analyses started with the characterization of the rumen content, which was carried out immediately after collection. With exception of $\mathrm{pH}$ and temperature, all the analyses were carried out on weekly basis for eight (8) weeks; $\mathrm{pH}$ and temperature of the feedstock under digestion were recorded at an interval of $6 \mathrm{~h}$. Total organic carbon was determined according to (Walkley and Black, 1934) as described by (Gelman et al., 2011); Nitrogen was carried out using (Kjeldahl, 1883) method as described by (Flindt and Lillebø, 2005); total solid and volatile solid were determined according to (APHA, 1998); moisture content was calculated by subtracting \%TS from 100 (Eckelman, 1996); ash content was determined using the ignition method in accordance with (APHA, 1998); a digital pH meter (JENWAY $3510 \mathrm{pH}$ Meter) was used to determine the $\mathrm{pH}$ value; temperature was determined using thermometer (PM-K, PAMAENS, Shanghai, China). A mass balance approach was used to estimate the theoretical gas yield from the TS/VS lost. Initial TS/VS of the feedstock was determined before feeding into the digesters and then on weekly basis for 8 weeks using the methods described above. The difference between the initial (mass of TS/VS fed) and the subsequent TS/VS (residual TS/VS in the digested feedstock) gave the quantity of TS/VS lost. It was presented as liters of biogas produced per gram TS/VS lost. This gave an index of process efficiency (Deressa et al., 2015). The arithmetic was done by using the equation:

$$
\frac{T S}{V S} \text { Lost }=\text { Intial } \frac{T S}{V S}-\text { Subsequent } \frac{T S}{V S}
$$

\section{Microbiological Analyses}

\section{Microbial Count}

The anaerobic mesophilic bacterial count was carried out according to (Association of Official Analytical Chemists, 1990); nutrient agar (for bacteria) and Potato Dextrose Agar (PDA) media were used for this purpose. Following anaerobic incubation, distinct pure colonies obtained on the plates were counted with colony counter (Shine Scientific Instruments) and the microbial count was calculated as follows: 


$$
\text { Number of Cell }=\frac{\Sigma C}{\left(n_{1}+0.1 \times n_{2}\right)(V \times d)}
$$

Where:

$\Sigma C=$ Sum of colonies counted on all the dishes retained from two successive dilutions

$V \quad=$ The volume of inoculum applied to each dish

$d=$ The dilution factor corresponding to the first counted dilution

$n_{1}=$ The number of dishes counted for the first counted dilution

$n_{2}=$ The number of dishes counted for the $1 / 10$ dilution of the second counted dilution

The results of the number of the microbial counts from the modified digester were compared with that of conventional one. A microbial count was carried out on weekly basis for 8 weeks.

\section{Identification of the Microbes}

Isolation and identification of fungal and bacterial as well as archaeal species was carried out using molecular approach. The extraction of the genomic DNA was carried out using Nucleo-pore gDNA Fungal/Bacterial Mini Kit (Genetix Biotech Asia Manual, 2018) according to the manufacturer's instruction. After extraction, the purified DNA was subjected to PCR for amplification (Genetix Biotech Asia Manual, 2018).

PCR reagents from Genetix Biotech Asia Prv. Ltd. were used to amplify V3-V4 regions of the $16 \mathrm{~S}$ rRNA with universal bacterial primers (515F/926R) and universal archaeal primers (Met86F/Met1340R); and $18 \mathrm{~S}$ rRNA with universal fungal primers (NS1/NS4).
The amplified DNA fragments were separated on $1.5 \%$ agoarose gel. The SureTrap PCR Clean-up Gel Extraction kit (Genetix Biotech Asia Manual, 2018) was used to elute the amplicons from the gel. The purified PCR products were sequenced using both the forward and reverse primers (above). The sequencing was carried out by Sanger sequencing (Dideoxy Chain-termination) method with Big-Dye terminator kit using ABI Sequencers (Thermo Fisher Scientific, USA). The 16S rRNA (for bacteria and archaea) and 18S rRNA (for fungi) sequences were submitted to GenBank and analyzed using the BLAST program in GenBank at National Center for Biotechnology Information website (http://www.ncbi.nlm.gov/BLAST).

\section{Results and Discussion}

\section{Results}

This section presents the results of the research work. Figure 2 shows the biogas plant developed, which is comprised of two digesters (modified and conventional one), each with a displacement chamber, from which the digested slurry drains into a single compost pit; the two digesters also share a single slurry tank.

\section{Results of Physicochemical Analyses}

Table 1 shows some characteristics of rumen content used in the present research work. The rumen content was found to contain a $\mathrm{C}: \mathrm{N}$ ratio of 34.07 , suggesting its suitability in biogas production; this is in consideration of the parameters determined, which were within the recommended range and therefore supporting the microbial growth and metabolism.

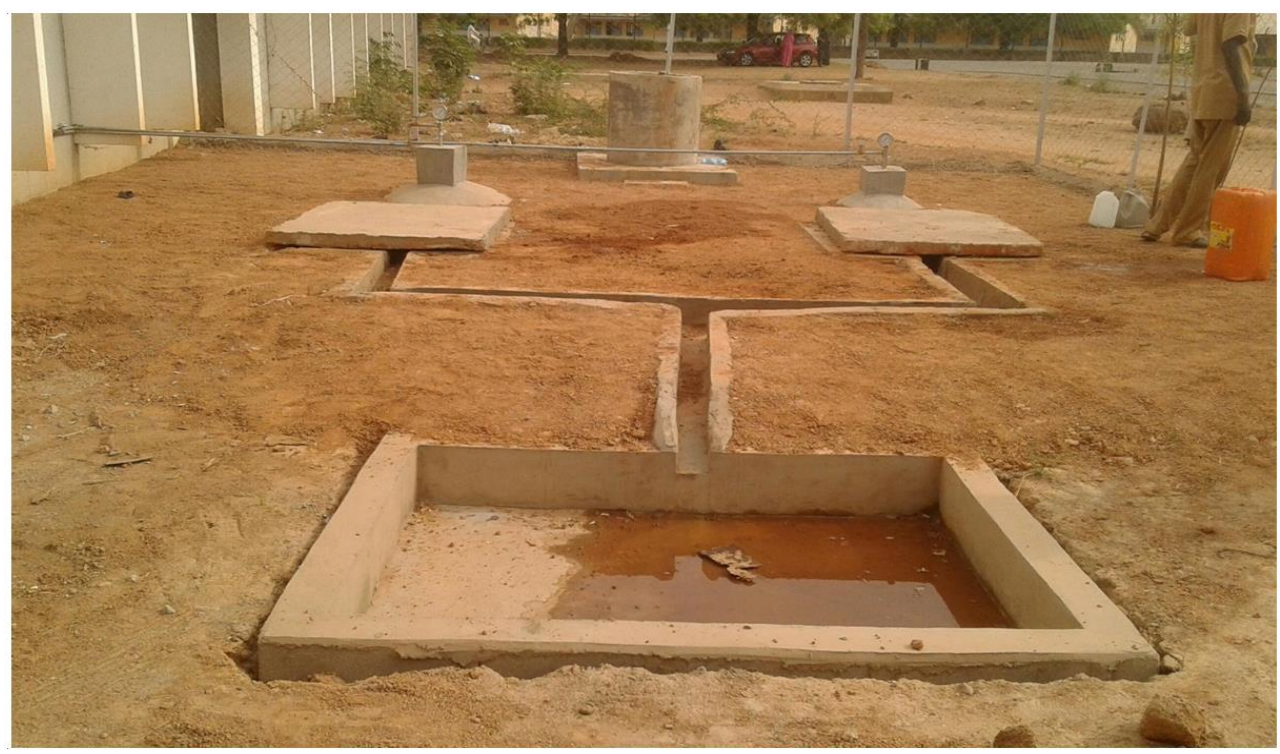

Fig. 2: The layout of the biogas plant 


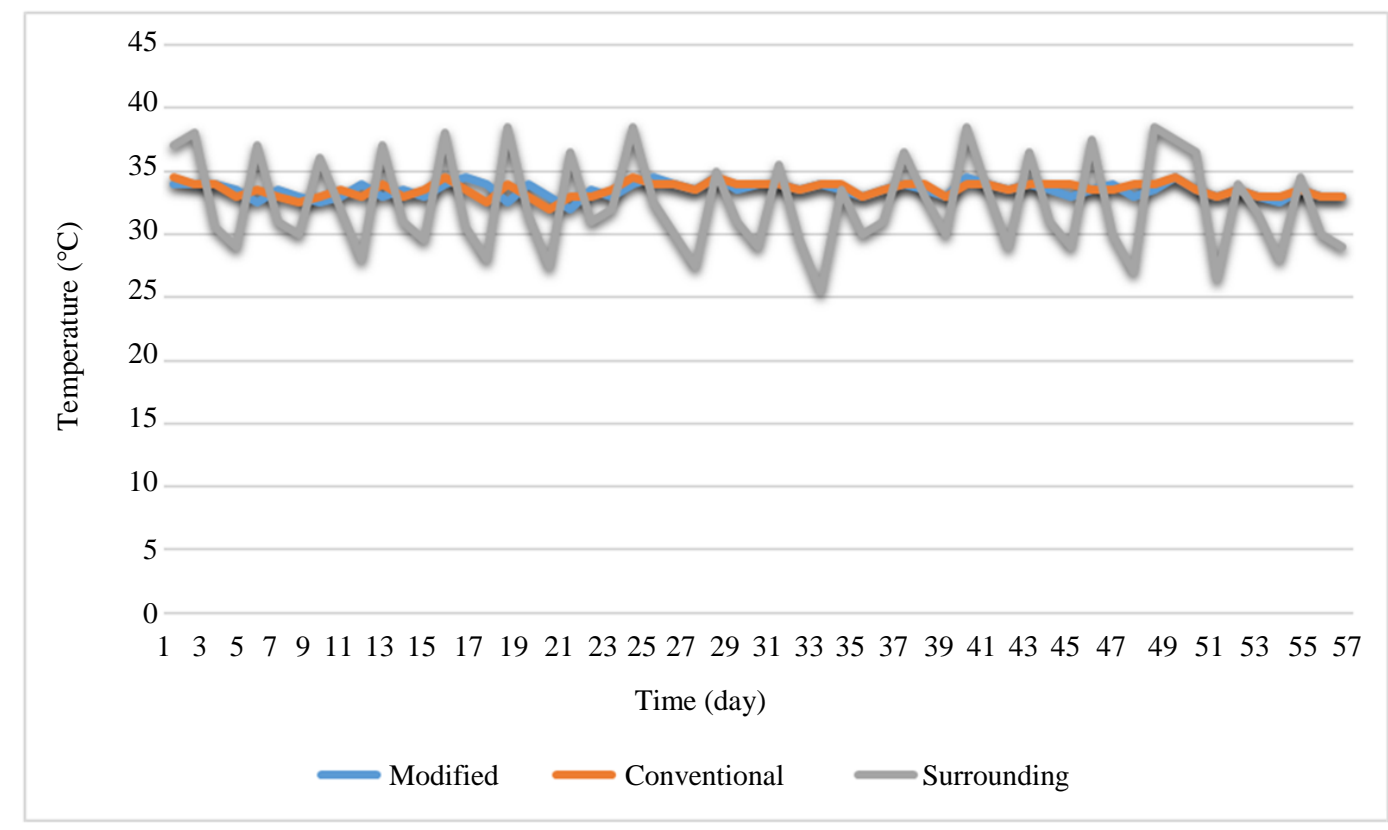

Fig. 3: Temperature monitoring in both modified and conventional digesters

Table 1: Characterization of Feedstock before Feeding

\begin{tabular}{llll}
\hline S/N & Parameters & Values & Recommended Value \\
\hline 1. & C:N & 34.07 & $25-35$ (Wellinger et al., 2013) \\
2. & Ash content & $27.53 \%$ & $<10 \%$ (Wellinger et al., 2013) \\
3. & Total solid & $19.23 \%$ & $8-16 \%$ (Marchaim, 1992) \\
4. & $\mathrm{pH}$ & 6.67 & $6-7$ (Wellinger et al., 2013) \\
5. & Temperature & $27.5^{\circ} \mathrm{C}$ & $20-45^{\circ} \mathrm{C}$ (Marchaim, 1992) \\
\hline
\end{tabular}

Figure 3 shows the mean temperatures of the modified and conventional digesters as well as the surrounding temperature. It was observed that, the fluctuation of temperature was highly minimized in both the digesters, ranging from 32 to $34.5^{\circ} \mathrm{C}$, compared to the surrounding temperature, which shows remarkable fluctuation of temperature throughout the hydraulic retention time, ranging from 25 to $38.5^{\circ} \mathrm{C}$.

Figure 4 presents the result of volatile acids production, which was qualitatively determined based on the detection of changes in $\mathrm{pH}$ of the slurry over a period covering the retention time. It was observed that there was a gradual drop in $\mathrm{pH}$ in the conventional digester throughout the retention time, which dropped from 6.67 on the feeding day to 5.57 after the 8th week. However, rapid drop in $\mathrm{pH}$ was observed in the modified digester from 6.67 on the feeding day to 4.95 on the fourth (4th) week and there was slight raise in $\mathrm{pH}$ to around 5.27 after 8 weeks of fermentation. It was noticed that the rapid drop in $\mathrm{pH}$ level in the modified digester was as a result of daily agitation of the feedstock.

Table 2 shows the result of the weekly determination of total solid and volatile solid in both the modified and conventional digesters. The Table reveals gradual decrease in both the TS and VS in the digesters. The change in VS in the modified digester was from 66.67 to $36.13 \%$, while in the conventional digester, VS drops from 69.94 to $54.23 \%$ after digestion. The TS in the modified digester was observed to drop from 12.49 to $3.82 \%$, while in the conventional digester, TS drops from 13.30 to $6.96 \%$ after 8 weeks of digestion.

From Table 3, the change in TS/VS in the modified digester was slightly higher than that of the conventional digester. The initial TS/VS of the slurry was 0.196 and the final TS/VS in the modified digester was 0.111 implying a difference of 0.085 , which was higher compared with 0.061 obtained in the conventional digester.

Figure 5 presents the graph of biogas yield at an interval of a week for 8 weeks. It can be seen that the graphs follow similar pattern, but with highest theoretical biogas yield (in $\mathrm{mg} / \mathrm{l}$ ) in the modified digester.

\section{Results of Microbial Analyses}

Table 4 shows a comparative analysis of the anaerobic mesophilic bacterial count between the modified and conventional digesters. In the first week, the highest mesophilic count was observed in the 
modified digester with a count of $2.6 \times 10^{4}$, with corresponding count of $2.2 \times 10^{4}$ in the conventional digester. Decrease in counts was observed in the modified digester from the second week $\left(2.4 \times 10^{4}\right)$ to 4 th week $\left(1.6 \times 10^{4}\right)$ and then started increasing in the 5 th week $\left(1.7 \times 10^{4}\right)$ to $2.4 \times 10^{4}$ in the 7 th week.
However, an increase in bacterial count $\left(2.6 \times 10^{4}\right)$ was recorded in the conventional digester in the second week, but with sharp drop $\left(1.7 \times 10^{4}\right)$ in the 3 rd week; followed by gradual increase in the subsequent weeks, until the 8th week when decrease in count from $2.2 \times 10^{4}$ to $2.1 \times 10^{4}$ was observed.

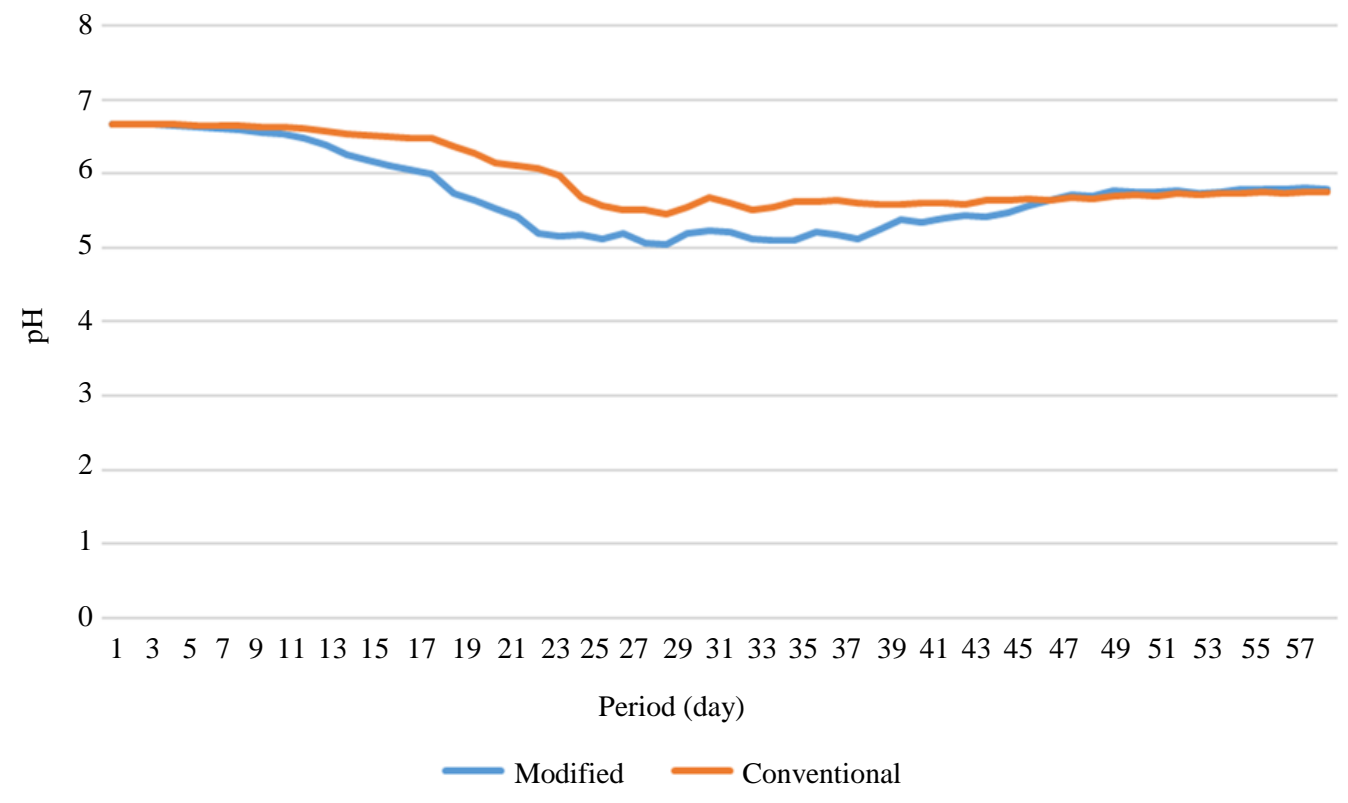

Fig. 4: Changes in $\mathrm{pH}$ in the modified and conventional digesters

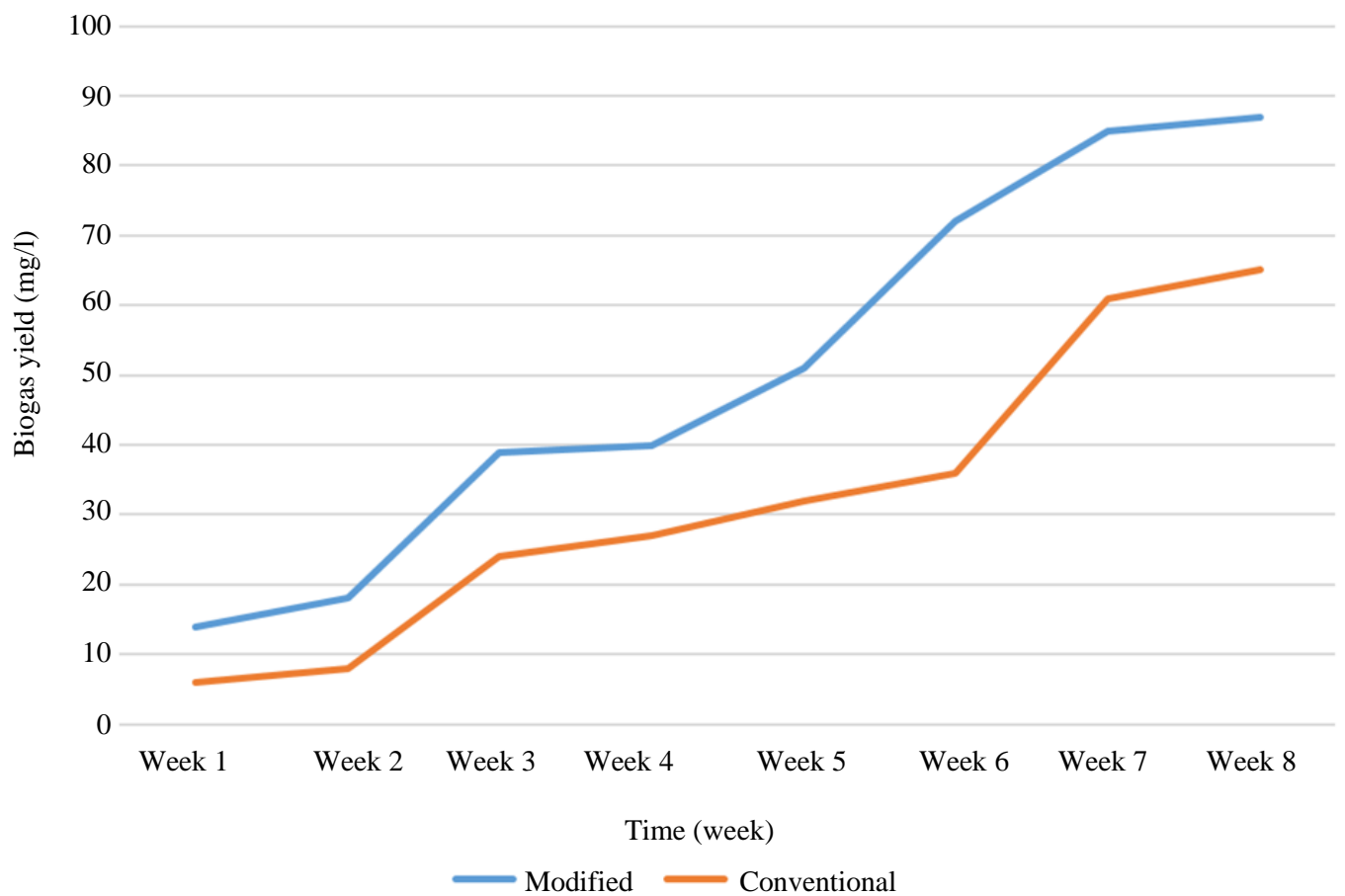

Fig. 5: Biogas yield per time in the modified and conventional digesters 
Table 2: Mean total and volatile solids in both the modified and conventional digesters

\begin{tabular}{|c|c|c|c|c|c|c|}
\hline \multirow{2}{*}{$\begin{array}{l}\text { Period } \\
\text { (Week) }\end{array}$} & \multicolumn{3}{|c|}{ Modified digester } & \multicolumn{3}{|c|}{ Conventional digester } \\
\hline & Mean TS $(\%)$ & Mean VS (\%) & TS/VS & Mean TS $(\%)$ & Mean VS $(\%)$ & TS/VS \\
\hline Week 1 & $12.49 \pm 0.53$ & $66.67 \pm 1.62$ & 0.187 & $13.30 \pm 0.40$ & $69.94 \pm 1.54$ & 0.190 \\
\hline Week 2 & $11.56 \pm 0.53$ & $64.93 \pm 1.00$ & 0.178 & $12.26 \pm 0.23$ & $65.24 \pm 0.81$ & 0.188 \\
\hline Week 3 & $9.87 \pm 0.45$ & $63.04 \pm 1.00$ & 0.157 & $11.01 \pm 0.49$ & $64.11 \pm 1.60$ & 0.172 \\
\hline Week 4 & $9.84 \pm 0.37$ & $63.17 \pm 1.26$ & 0.156 & $10.73 \pm 0.47$ & $63.46 \pm 1.01$ & 0.169 \\
\hline Week 5 & $8.98 \pm 0.28$ & $61.87 \pm 1.70$ & 0.145 & $10.14 \pm 0.16$ & $61.72 \pm 2.00$ & 0.164 \\
\hline Week 6 & $6.85 \pm 0.66$ & $55.33 \pm 4.17$ & 0.124 & $9.39 \pm 0.38$ & $58.67 \pm 1.36$ & 0.160 \\
\hline Week 7 & $4.19 \pm 0.54$ & $37.67 \pm 6.13$ & 0.111 & $7.49 \pm 0.23$ & $55.32 \pm 1.91$ & 0.135 \\
\hline Week 8 & $3.82 \pm 0.21$ & $36.13 \pm 0.27$ & 0.109 & $6.96 \pm 0.16$ & $54.23 \pm 1.33$ & 0.131 \\
\hline
\end{tabular}

Table 3: TS/VS lost in modified and conventional digesters (Initial TS/VS $=0.196$ )

\begin{tabular}{|c|c|c|c|c|c|c|}
\hline \multirow{2}{*}{$\begin{array}{l}\text { Interval } \\
\text { (Week) }\end{array}$} & \multicolumn{3}{|c|}{ Modified digester } & \multicolumn{3}{|c|}{ Conventional digester } \\
\hline & TS/VS & TS/VS Lost & TBY (mg/l) & TS/VS & TS/VS Lost & $\mathrm{TBY}(\mathrm{mg} / \mathrm{l})$ \\
\hline Week 1 & 0.187 & 0.014 & 14 & 0.190 & 0.006 & 6 \\
\hline Week 2 & 0.178 & 0.018 & 18 & 0.188 & 0.008 & 8 \\
\hline Week 3 & 0.157 & 0.039 & 39 & 0.172 & 0.024 & 24 \\
\hline Week 4 & 0.156 & 0.040 & 40 & 0.169 & 0.027 & 27 \\
\hline Week 5 & 0.145 & 0.051 & 51 & 0.164 & 0.032 & 32 \\
\hline Week 6 & 0.124 & 0.072 & 72 & 0.160 & 0.036 & 36 \\
\hline Week 7 & 0.111 & 0.085 & 85 & 0.135 & 0.061 & 61 \\
\hline Week 8 & 0.109 & 0.087 & 87 & 0.131 & 0.065 & 65 \\
\hline
\end{tabular}

Table 4: Anaerobic Mesophilic Bacterial Counts (MAMBC) in modified and conventional digesters

\begin{tabular}{lll}
\hline Period (Week) & MAMBC in modified digester $(\mathrm{cfu} / \mathrm{mg})$ & MAMBC in conventional digester $(\mathrm{cfu} / \mathrm{mg})$ \\
\hline Week 1 & $2.6 \times 10^{4}$ & $2.2 \times 10^{4}$ \\
Week 2 & $2.4 \times 10^{4}$ & $2.6 \times 10^{4}$ \\
Week 3 & $2.0 \times 10^{4}$ & $1.7 \times 10^{4}$ \\
Week 4 & $1.6 \times 10^{4}$ & $1.8 \times 10^{4}$ \\
Week 5 & $1.7 \times 10^{4}$ & $2.2 \times 10^{4}$ \\
Week 6 & $1.9 \times 10^{4}$ & $2.2 \times 10^{4}$ \\
Week 7 & $2.4 \times 10^{4}$ & $2.1 \times 10^{4}$ \\
Week 8 & $2.3 \times 10^{4}$ & $2.1 \times 10^{4}$ \\
\hline
\end{tabular}

Table 5: Anaerobic fungal counts in modified and conventional digesters

\begin{tabular}{lll}
\hline Period (Week) & Modified digester $(\mathrm{cfu} / \mathrm{mg})$ & Conventional digester $(\mathrm{cfu} / \mathrm{mg})$ \\
\hline Week 1 & $4.0 \times 10^{2}$ & $4.0 \times 10^{2}$ \\
Week 2 & $4.0 \times 10^{2}$ & $4.0 \times 10^{2}$ \\
Week 3 & $4.0 \times 10^{2}$ & $4.0 \times 10^{2}$ \\
Week 4 & $3.0 \times 10^{2}$ & $3.0 \times 10^{2}$ \\
Week 5 & $3.0 \times 10^{2}$ & $3.0 \times 10^{2}$ \\
Week 6 & $3.0 \times 10^{2}$ & $3.0 \times 10^{2}$ \\
Week 7 & $3.0 \times 10^{2}$ & $4.0 \times 10^{2}$ \\
Week 8 & $4.0 \times 10^{2}$ & $4.0 \times 10^{2}$ \\
\hline
\end{tabular}

Table 6: Bacteria Isolated and Identified in the Feedstock before and after digestion

\begin{tabular}{lll}
\hline Microbial category & Accession Number & Organism \\
\hline Bacteria & MK350333 & Lactobacillus acidophilus \\
& MK350334 & Bacteroides nordii \\
& MK350335 & Clostridium perfringens \\
& MK350336 & Proteus vulgaris \\
Methanogenic Archaea & MK355515 & Clostridium acetobutylicum \\
& MK350337 & Methanosarcina sicilia \\
Fungi & MK350338 & Methanosarcina mazei \\
& MK355516 & Methanobrevibacter ruminantium \\
& MK368534 & Fusarium solani \\
& MK368535 & Fusarium graminearum \\
& MK368536 & Aspergillus niger \\
& MK368537 & Penicillium specie \\
\hline
\end{tabular}


Table 5 presents the result of fungal count found in both the modified and conventional digesters carried out on weekly basis for a period of 8 weeks. The fungal counts were uniform in both the digesters throughout the span of the research and counts of $4.0 \times 10^{2} \mathrm{cfu} / \mathrm{mg}$ were obtained in both up to the third week; then dropped to $3.0 \times 10^{2}$ in the fourth to sixth week.

Table 6 presents the result of the identification of microorganisms in the study.

\section{Discussion}

The present study was carried out with the desire to test the hypothesis that the modification of some features of the conventional household fixed-dome anaerobic digester through the application of simple engineering design could improve its quality and enhance the microbial utilization of rumen content in biogas production. The study focuses on addressing the kinetics effects of manually stirring the mixture in the modified biodigester.

Physicochemical parameters observed in the present study were temperature, $\mathrm{pH}$, TS and VS; these are the factors that affect microbial biodegradation of organic waste in anaerobic digestion system (Wellinger et al., 2013) and change with change in mixing rate; this have overall effect on microbial growth (counts) and metabolism. The temperatures in both the modified and conventional digesters were relatively uniform and this relative uniformity had to do with the bigger size of the digester, which resists fluctuation due to changes in the surrounding temperature. The work of (Asikong et al., 2016) have supported this view.

A decrease in $\mathrm{pH}$ was observed particularly during the 3rd to 4th week of digestion, which is attributed to $\mathrm{CO}_{2}$ and high volatile fatty acids production during the fermentation process. The decrease in the $\mathrm{pH}$ level in the modified digester as compared to conventional digester was also attributed to daily agitation of the slurry using the improvised stirrer. These changes are attributed to the effect of modification of digester in the presence study. This finding agrees with the work of (Beevi et al., 2013).

Microorganisms are the key producers of biogas and their number determines the favorability of condition in the anaerobic digester as well as the volume of biogas produced. Relatively low bacterial and fungal counts observed in the first week, particularly in the conventional digester, might be attributed to factors such as digestibility of the feedstock, high solid content and uneven distribution of microorganisms and nutrients in the digester. There was increase in bacterial count in the conventional digester in the second week when the bacteria started adapting to the new environment within the digester. The sudden decrease in bacterial count in the third week had to do with accumulation of organic acids, $\mathrm{CO}_{2}$ as well as toxic bacterial metabolites; the count stabilizes in the subsequent weeks. The count was relatively higher in the modified digester during the first week, but drops during the second week presumably due to rapid accumulation of organic acids enhanced by daily agitation, which resulted in the drop of $\mathrm{pH}$ level, thus inhibiting bacterial growth. Anaerobic fungal counts were uniform throughout the hydraulic retention time, suggesting high acidic resistance of the fungi. It was observed that, agitation enhances fermentation with resultant increased acids production. This increases the quantity of acids that undergo acetogenesis, with subsequent increase in the quantity of acetate that undergo acetoclastic methanogenesis and eventually results in high biogas yield.

With regard to yield in biogas production, reduction in volatile solid concentration determines the theoretical biogas yield. In this study, the VS in the modified digester reduced to $36.13 \%$ from the initial value of $66.67 \%$ with corresponding yield of 0.085 litre per gram (85 ml/g), which was higher when compared with conventional digester with VS reduction from 69.94 to $54.23 \%$ and a biogas yield of $65 \mathrm{ml} / \mathrm{g}$. According to the statistical analysis (a paired t-test) conducted, the mean biogas yield $($ mean $=18.375$; Standard Deviation $=$ 9.054; $\mathrm{N}=8$ ) was found to be significantly greater than zero; $\mathrm{t}$-Stat $=5.74$; two-tail $\mathrm{p}=0.001$, providing evidence that the modification is effective in producing higher theoretical biogas. A 95\% confidence interval about mean biogas yield was (10.805, 25.945). Moreover, the p-value (two-tail) was found to be less than the alpha level chosen (i.e., 0.05); and that, the tvalue (5.74) was greater than the t-critical (two-tail) value (2.365). This led to the acceptance of the hypothesis that modification of the digester improves the biogas yield in anaerobic digestion of rumen content. The higher theoretical biogas yield in the modified digester was attributed to daily agitation of the slurry. This agrees with the work of (Klocke et al., 2007), in which stirring was found to improved biogas production.

\section{Conclusion}

The microbial utilization of rumen content was found to be favoured by the effects of manual stirring of the mixture in a biodigester. The daily agitation in the modified digester facilitates the increase in the rate of fermentation in the modified digester; the rate of anaerobic digestion determined by the reduction in total solid and volatile solid, was also higher. Moreover, subsequent theoretical biogas production was higher in the modified digester $(87 \mathrm{mg} / \mathrm{l})$ compared to $65 \mathrm{mg} / \mathrm{l}$ produced in the conventional digester. The microorganisms identified were: Lactobacillus acidophilus, Bacteroides nordii, Clostridium perfringens, Clostridium acetobutylicum, Proteus vulgaris, Methanosarcina sicilia, Methanosarcina mazei, Methanobrevibacter ruminantium, Fusarium solani, 
Fusarium graminearum, Aspergillus niger and Penicillium specie.

Optimization of biogas production in anaerobic digestion system should be geared towards the modification of digester with a view to improving the mixing rate through agitation at least once or twice a day to ensure uniform distribution of nutrients and microorganisms and also to break any scum that may prevent the release of gas from the slurry. Frequent stirring should be avoided to prevent accumulation of volatile acids which leads to inhibition of microbial growth and metabolism. Pretreatment approaches should be considered to improve microbial utilization of recalcitrant feedstocks such as rumen content and some plant materials in anaerobic digestion system.

\section{Acknowledgment}

The authors would like to thank The Dirctorate of Research, Innovation and Partnership (DRIP), Bayero University, Kano, Nigeria and the Tertiary Education Trust Fund (TETFund) for their support on this research work. The authors would also like to extend their appreciation to Mustapha Ishaq and Mubarak Sani Yakub of the Department of Biological Sciences, Bayero University, Kano, for their immense contributions.

\section{Author's Contributions}

All the authors in the present study have contributed a lot; as the research work is multidisciplinary in nature, so the authors; everyone has played his role diligently.

\section{Ethics}

This study is free of any ethical issue.

\section{References}

APHA. (1998). Standard Methods for the Examination of Water and Wastewater. 20th edition. Washington, D.C, USA.

Asikong, B. E., Idire, S. O., \& Tiku, D. R. (2016). Microorganisms Associated with Biogas Production Using Vegetable (Telfairia occidentalis) Wastes, Banana Peel and Pig Dung as Substrates. Microbiology Research Journal International, 1-12.

Association of Official Analytical Chemists (1990). Official Methods of Analysis.

Aurélio, M. S. B. (2011). Biofuel Production - Recent Developments and Prospects. Janeza Trdine 9, 51000 Rijeka, Croatia.

Beevi, S. B., Jose, P. P., \& Madhu, G. (2013). Effect of total solid concentration on anaerobic digestion of the organic fraction of municipal solid waste. International Journal of Scientific and Research Publications, 3(8); 57-72.
Ben-Hasson, R.M., Ghaly, A.E., \& Singh, R.K. (1985). Design and evaluation of no-mix energy efficient anaerobic digester. In: Proceedings, Annual Meeting, Canadian Society of Agricultural Engineering, Charlottetown, P.E.I. p. 23-27.

Chandel, A.K. (2019). Sustainable Approaches for Biofuels Production Technologies: From Current Status to Practical Implementation. Biofuel and Biorefinery Technologies; Volume 7 (eBook), Springer International Publishing AG, Switzerland.

Chapman, D. (1989). Mixing in anaerobic digesters: state of the art. In: Cheremisinoff, P. (Ed.), Encyclopedia of Environmental Control Technology, vol. 3. Gulf Publishing Company, Houston, pp. 325-354.

Chen, T., Chynoweth, D.P., \& Biljetina, R. (1990). Anaerobic digestion of municipal solid waste in a nonmixed solids concentrating digester. Applied Biochemistry and Biotechnology, 24- 25, 533-544.

Cherdthong, A., Wanapat, M., Saenkamsorn, A., Waraphila, N., Khota, W., Rakwongrit, D., ... \& Gunun, P. (2014). Effects of replacing soybean meal with dried rumen digesta on feed intake, digestibility of nutrients, rumen fermentation and nitrogen use efficiency in Thai cattle fed on rice straw. Livestock Science, 169, 71-77.

Dague, R. R., McKinney, R. E., \& Pfeffer, J. T. (1970). Solids retention in anaerobic waste treatment systems. Journal of Water Pollution and Control Federation, Part 242 (2), R29- R46.

Deressa, L., Libsu, S., Chavan, R. B., Manaye, D., \& Dabassa, A. (2015). Production of Biogas from Fruit and Vegetable Wastes Mixed with Different Wastes. Environment and Ecology Research 3(3): 65-71.

Diaz, L., \& Trezek, G. (1977). Biogasification of a selected fraction of municipal solid wastes. Compositional Science, 8-13.

Eckelman, C. A. (1996). Wood Moisture Calculations. Forestry and Natural Resources, p. 1-18.

Flindt, M. R., \& Lilleb $\varnothing$, A. I. (2005). Determination of total nitrogen and phosphorus in leaf litter. In Methods to study litter decomposition (pp. 53-59). Springer, Dordrecht.

Gelman, F., Binstock, R., \& Halicz, L. (2011). Application of the Walkley-Black Titration for Organic Carbon Quantification in Organic Rich Sedimentary Rocks. Geological Survey for Israel, Report GSI/13/2011.

Genetix Biotech Asia Manual (2018); Nucleo-Pore, www.genetixbiotech.com

Georgia Gwinnett College [GGC] Model for Pakistan [2009]. Construction Manual. https://www.scribd.com/document/93764690/Constr uction-Manual-Modified-GGC-Model-Biogas-PlantFor-Pakistan-2009 
Hashimoto, A.G. (1983). Effect of mixing duration and vacuum on methane production rate from beef cattle waste. Biotechnology and Bioengineering, 24, 9-23.

Ho, C.C., \& Tan, Y.K. (1985). Anaerobic treatment of palm oil mill effluent by tank digesters. Journal of Chemical Technology and Biotechnology, 35, 155- 164.

James, S., Wiles, C., Swartzbaugh, J., \& Smith, R. (1980). Mixing in large- scale municipal solid waste-sewage sludge anaerobic digesters. In: Biotechnology and Bioengineering Symposium, vol. 10, pp. 259- 272.

Karim, K., Klasson, K.T.,Hoffmann, R., Dresher, S.R.,DePaoli, D.W., \& AI-Dahhan, H. (2003). Anaerobic digestion of animal waste: effect of mixing. Transactions on Ecology and the Environment, vol 62.

Karim, K., Hoffmann, R., Klasson, K., \& Al-Dahhan, M.H. (2005). Anaerobic digestion of animal waste: Waste strength versus impact of mixing. Bioresource Technology, 96, 1771-1781.

Kjeldahl, J. (1883) "Neue Methode zur Bestimmung des Stickstoffs in organischen Körpern" (New method for the determination of nitrogen in organic substances), Zeitschrift für analytische Chemie, 22 (1): 366-383.

Klocke, M., Mähnert, P., Mundt, K., Souidi, K., \& Linke, B. (2007). Microbial community analysis of a biogas-producing completely stirred tank reactor fed continuously with fodder beet silage as monosubstrate. Systematic and applied microbiology, 30(2), 139-151.

Lema, J.M., Mendez, R., Iza, J., Garcia, P., \& Fernandez-Polanco, F. (1991). Chemical reactor engineering concepts in design and operation of anaerobic treatment processes. Water Science and Technology, 24, 79-86.
Marchaim, U. (1992). Biogas processes for sustainable development. Food and Agriculture Organization, United Nations Press. http://www.fao.org/3/t0541e/T0541E0a.htm. Visited 23/3/2018.

Miertus, S. (2007). Biofuels: Technology Status and Future Trends, Technology Assessment and Decision Support Tools. International Centre for Science and High Technology United Nations Industrial Development Organization, ICS-UNIDO.

Mills, P.J. (1979). Minimization of energy input requirements of an anaerobic digester. Agricultural Wastes 1, 57-59.

Parkin, G.F., \& Owen, W.F. (1986). Fundamentals of anaerobic digestion of wastewater sludges. Journal of Environmental Engineering, 112, 867-920.

Sebola, M.R., Mokgatle, L., Aboyade, A., \& Muzenda, E. (2013). Production of Biogas through Anaerobic Digestion of various Waste: Review. International Conference on Chemical, Integrated Waste Management and Environmental Engineering (ICCIWEE, 2014) April 15-16, 2014 Johannesburg.

Smith, R.J., Hein, M.J., \& Greinier, T.H. (1979). Experimental methane production from animal excreta in pilot-scale and farm-size units. Journal of Animal Sciences, 48, 202-217.

Stenstrom, M., Ng, A., Bhunia, P., \& Abramson, S. (1983). Anaerobic digestion of municipal solid waste. Journal of Environmental Engineering, 109, 1148- 1158.

Walkley, A., \& Black, I.A. (1934). An examination of Degtjareff method for determining soil organic matter and a proposed modification of the chromic acid titration method. Soil Sciences, 37: 29-37.

Wellinger, A., Murphy, J., \& Baxter, D. (2013). The Biogas Handbook: Science, Production and Applications; 1st Edition; Woodhead Publishing. Hoboken, NJ, USA, 2003; pp. 23-51. 